\title{
Chronomodulated press-coated pulsatile therapeutic system for aceclofenac: optimization of factors influencing drug release and lag time
}

This article was published in the following Dove Press journal:

ChronoPhysiology and Therapy

21 February 2011

Number of times this article has been viewed

\author{
Sumit Patil ${ }^{1}$ \\ Swati Pund ${ }^{2}$ \\ Amita Joshi ${ }^{2}$ \\ Chamanlal J Shishoo \\ Aliasgar Shahiwala' \\ 'Department of Pharmaceutics, \\ National Institute of Pharmaceutical \\ Education and Research (NIPER), \\ Ahmedabad, India; ${ }^{2}$ Department of \\ Pharmaceutics, BV Patel PERD Centre, \\ Ahmedabad, India
}

Background: The objective of this study was to develop and evaluate a press-coated pulsatile drug delivery system intended for treatment of early morning stiffness and symptomatic relief from pain in patients with rheumatoid arthritis.

Methods: The formulation involved press coating of a rupturable coat around a rapidly disintegrating core tablet of aceclofenac. A three-factor, two-level, full factorial design was used to investigate the influence of amount of glyceryl behenate, amount of sodium chloride in the coating composition, and the coating level on the responses, ie, lag time to release and amount of aceclofenac released in 450 minutes.

Results: Glyceryl behenate and the coating level had a significant influence on lag time, while sodium chloride helped in the rupture of the coat by acting as a channeling agent. After the coat was ruptured, the core tablet showed a rapid release of aceclofenac due to the presence of Ac-Di-Sol ${ }^{\circledR}$. Graphical analysis of effects by Lenth's method and Bayesian analysis of coefficients enabled identification of variables active on the selected responses. The optimized formulation comprised $20 \% \mathrm{w} / \mathrm{w}$ glyceryl behenate and $2.2 \% \mathrm{w} / \mathrm{w}$ sodium chloride with a $650 \mathrm{mg}$ coating level, and showed a desired lag time of 358.23 minutes, which mimics the fluctuating symptoms of rheumatoid arthritis, followed by rapid release of aceclofenac.

Keywords: chronotherapy, pulsatile delivery, rupturable coat, aceclofenac

\section{Introduction}

In recent years, oral drug delivery systems with zero order sustained-release kinetics have been developed to control drug release using various mechanisms, including matrices with controllable swelling, diffusion, erosion, and osmotically driven systems. ${ }^{1}$ Efforts are being made to avoid typical plasma concentration peaktrough fluctuations and to reduce frequency of drug administration for better patient compliance. Recently, novel systems have been developed that release the drug after a programmable lag time.

Changes in the biological rhythms of the human body (ie, chronobiology) may precipitate serious medical conditions, eg, myocardial infarction or stroke, in addition to the manifestation and severity of symptoms of chronic diseases, including allergic rhinitis, asthma, nocturnal acid reflux, and arthritis. For such chronopathological conditions, chronotherapeutic systems play an important role, because these formulations take into account probable time-dependent variation in the risk or symptoms of disease. Such systems are designed to enable a pulsatile release of drug after a predetermined off-release period (lag time) which mimics the chronopathological symptoms. ${ }^{2,3}$
Dubai Pharmacy College, PO Box 19099,

Dubai, United Arab Emirates

Tel +9I 7927439375

Fax +91 7927450449

Email alishahiwala@gmail.com 
A pulsatile therapeutic system can be a single unit (eg, a tablet or capsule) or be multiparticulate (eg, pellets)., Capsule-based pulsatile release systems have also been developed which are coated with a water-impermeable or semipermeable membrane containing a hydrogel polymer plug which swells with time after coming into contact with gastrointestinal fluid, and exerts an internal pressure leading to release of drug after rupture of the membrane..$^{6-8}$

Pulsatile tablet formulations are manufactured with a rapid-release core (reservoir) encased in a barrier layer formed by rupturable press coating or liquid coating of erodible and swelling polymer. ${ }^{9-11}$ Polymers like various grades of Eudragit ${ }^{\circledR}$ or ethyl cellulose have been tested as film coating to achieve the desired lag time. ${ }^{11-14}$ However, a potential problem associated with the film-coated pulsatile systems is delayed drug release after loss of the barrier coat. ${ }^{14}$ To get immediate release of the drug after a desired lag time, press-coated systems with a rupturable coat have been suggested. ${ }^{15,16}$ In addition, press coating overcomes the drawbacks of a liquid coating because it does not require use of a solvent and requires a relatively shorter manufacturing process. With newer technologies, tablet compression and press coating can be achieved in a single step. In addition, it is possible to control lag time by changing the coating thickness and composition. ${ }^{17}$

Aceclofenac, a nonsteroidal anti-inflammatory drug, is used for the symptomatic relief of pain and joint stiffness in patients suffering from rheumatoid arthritis, which is characterized by diurnal variation in circulating levels of proinflammatory cytokines, interleukin-6 and/or tumor necrosis factor- $\alpha$. Due to this diurnal variation, many symptoms and signs of active rheumatoid arthritis are manifested in the morning. ${ }^{18}$ To coincide with the release of these inflammatory cytokines and peak plasma aceclofenac levels, a press-coated pulsatile tablet (PCPT) formulation was developed to alleviate the symptoms of morning stiffness in patients with rheumatoid arthritis. PCPT, on oral administration at bed-time, releases aceclofenac after a desired lag time of about 360 minutes which corresponds with peak levels of proinflammatory mediators.

The current study illustrates the formulation, characterization, and optimization of a PCPT for aceclofenac. The system is based on a rupturable coat in which glyceryl behenate is incorporated in the coating composition to provide the desired lag time of 360 minutes, and sodium chloride acts as the channeling agent to aid rupture of the coat. Ac-Di-Sol ${ }^{\circledR}$ as a superdisintegrant in the core tablet enables rapid release of aceclofenac after the coat is ruptured.
A computer-aided optimization technique using a threefactor, two-level, full factorial design was used to investigate the effect of three factors, ie, amount of glyceryl behenate, amount of sodium chloride, and coating level. Experimental design and statistical modeling are essential tools for the development and understanding of complicated formulations and processes. These allow efficient experimentation covering a large number of factors which are varied together over a set of experiments, in contrast with the traditional approach of varying each factor while keeping other factors constant, which may fail to identify any interactions between these factors.

\section{Materials and methods Materials}

Aceclofenac was donated by Astron Research Ltd, India. Microcrystalline cellulose (Avicel PH101, Signet Chemical Corporation, India), Ac-Di-Sol (FMC Biopolymer, Signet Chemical Corporation), iron oxide III red (BASF, Germany) magnesium stearate (Loba Chemie Pvt Ltd, India), and Aerosil ${ }^{\circledR} 200$ (Degussa, Frankfurt, Germany) were used as components of the core tablets. The coating components were glyceryl behenate (Compritol 888, Gattefosse, St Priest, Cedex, France), dicalcium phosphate (Rankem, India) and polyvinylpyrrolidone (Kollidon ${ }^{\circledR}$ K30, BASF). All other ingredients and reagents were of analytical grade and were used as received.

\section{Preparation of press-coated pulsatile tablets Drug-excipient compatibility studies}

Drug-excipient compatibility was studied using differential scanning calorimetry (Perkin Elmer DSC-7, Norwalk, CT). The physical mixtures of aceclofenac and various excipients were prepared by trituration in a dry mortar for two minutes. The samples were heated in sealed aluminum pans under nitrogen flow $(40 \mathrm{~mL} / \mathrm{min})$ at a scanning rate of $10^{\circ} \mathrm{C} / \mathrm{min}$ from $25^{\circ} \mathrm{C}$ to $250^{\circ} \mathrm{C}$. An empty aluminum pan was used as a reference. The heat flow as a function of temperature was measured for the pure aceclofenac and aceclofenac-excipient mixtures.

\section{Experimental design}

A number of preliminary experiments were conducted to determine the formulation and parameters by which the process resulted in PCPT. NEMRODW software (LPRAI SARL, Marseille, France) was used in our study for generation and evaluation of the statistical experimental design. A three-factor, two-level, full factorial design was employed for the optimization 
procedure. The amount of glyceryl behenate in the rupturable coating $\left(\mathrm{X}_{1}, \% \mathrm{w} / \mathrm{w}\right.$ of coating), coating level $\left(\mathrm{X}_{2}, \mathrm{mg}\right)$, and amount of sodium chloride $\left(\mathrm{X}_{3}, \% \mathrm{w} / \mathrm{w}\right.$ of coating $)$ were selected as the independent variables, whereas lag time ( $\mathrm{Y}_{1}$, minutes) and the amount of aceclofenac released in 450 minutes $\left(\mathrm{Y}_{2}\right.$, percent) were chosen as the dependent variables. Table 1 summarizes these factors with corresponding levels and the responses studied, whereas experimental formulations are listed in Table 2. The factors were selected to measure the change in response from one extreme factor to another and for determining interactions, if any, among the factors with their best levels for optimizing the considered experimental responses.

\section{Preparation of core tablets of aceclofenac}

The core tablets were prepared by direct compression. Aceclofenac (100 mg/tablet), Avicel PH101 (36.95\% w/w), and Ac-Di-Sol (7\% $\mathrm{w} / \mathrm{w}$ ) were mixed in a small-scale planetary mixer (Kalweka, Karnavati Eng Ltd, India) for 10 minutes. Magnesium stearate $(1 \% \mathrm{w} / \mathrm{w})$ and Aerosil $(0.5 \% \mathrm{w} / \mathrm{w})$ were added to the mixture and mixed for a further minute. Iron (III) oxide red $(0.5 \% \mathrm{w} / \mathrm{w}$ of tablet blend) was used as the coloring agent in the core for easy visibility of tablet disintegration after rupture of the coat. Tablets were compressed with an average weight of $185 \pm 5 \mathrm{mg}$ using a single-station tablet compression machine (Cadmach, India).

\section{Preparation of granulate for press coating and press coating of prepared core tablets of aceclofenac} Glyceryl behenate, dicalcium phosphate, Kollidon K-30, and sodium chloride were sifted though the mesh (pore size $425 \mu \mathrm{m}$ ) and homogeneously mixed in a small-scale planetary mixer for 10 minutes. Subsequently, the mixture was granulated using water. The granules thus formed were dried in an oven at $40^{\circ} \mathrm{C}$ for 20 minutes to obtain residual moisture less than $2.5 \%$. The dried granules were passed through the

Table I Three-factor, two-level full factorial experimental design: factors selected and responses measured

\begin{tabular}{llr}
\hline Factors & $\begin{array}{l}\text { Levels of the factors used } \\
\text { in the aceclofenac PCPT } \\
\text { formulation }\end{array}$ \\
\cline { 2 - 3 } & -1 & + I \\
\hline$X_{1}=$ amount of GB & 20 & 40 \\
$(\%$ w/w of coating) & & 650 \\
$X_{2}=$ Coating level (mg) & 450 & 5 \\
$X_{3}=$ amount of sodium & 0 & \\
chloride (\% w/w of coating) & & \\
Responses & & \\
$Y_{1}=$ Lag time (min.) & $Y_{2}=$ aceclofenac released & \\
\hline
\end{tabular}

Abbreviation: PCPT, press-coated pulsatile tablet. mesh (pore size $710 \mu \mathrm{m}$ ) and lubricated with a 2:1 mixture of magnesium stearate and Aerosil. The core tablets were presscoated with different coating levels as per the experimental design (Table 2). Half of the granulate required was weighed and transferred into a $10.86 \mathrm{~mm}$ die. Next, the core tablet was centrally placed on the granule bed. The remaining half of granulate was added into the die and compressed using a single-station tablet compression machine.

\section{Physicochemical characterization of core and PCPT of aceclofenac}

The thickness, diameter, and hardness of the tablets $(n=6)$ were determined using a Vernier Caliper (Mitutoyo Digimatic Caliper, Japan) and the tablet strength tester (EH01; Electrolab, India), respectively. The friability ( $\%$ ) of the tablets was determined using a Roche Friabilator (EF-2; Electrolab) and uniformity of tablet weight $(n=20)$ was evaluated as per pharmacopoeial guidelines. ${ }^{19}$ The disintegration time of the core tablets was determined using a disintegration tester USP (ED-2AL; Electrolab), and the aceclofenac content of the tablets was assayed in triplicate by a validated reversed phase high-pressure liquid chromatography method..$^{20}$

\section{In vitro aceclofenac release studies}

Dissolution studies were carried out using USP XXIII Apparatus I (Electrolab) at a rotation speed of $100 \mathrm{rpm}$ and at $37 \pm 0.5^{\circ} \mathrm{C}$ using $900 \mathrm{~mL}$ of $0.1 \mathrm{~N} \mathrm{HCl}$ for two hours, followed by $900 \mathrm{~mL}$ of $\mathrm{pH} 6.8$ phosphate buffer as the dissolution media. At appropriate time intervals, dissolution samples were withdrawn and filtered through $0.45 \mu \mathrm{m}$ syringe filters (Qualisil, LCGC Chromatography Solutions P Ltd, India). Samples were analyzed by ultraviolet visible spectrophotometry (Shimadzu UV-2450 ultraviolet-visible scanning spectrophotometer, Japan) at $273 \mathrm{~nm} .{ }^{20}$ The amount of aceclofenac dissolved in the dissolution media was then determined from the calibration curve and the cumulative percentage of aceclofenac released was calculated.

\section{Dissolution-ex vivo permeation study using everted rat intestine}

Intestine was isolated from a male Wistar rat. A median incision was made into the abdomen, the small intestine was freed, and the lumen was carefully cleared with a Krebs-Ringer solution. The intestinal segment was everted and the distal $5 \mathrm{~cm}$ part was used. One end of the isolated everted intestinal segment was fixed to a straight cannula and at the other end tied using a thread to a $1 \mathrm{~g}$ weight..$^{21,22}$ The system was filled with Krebs-Ringer solution and was completely immersed 
Table 2 Aceclofenac PCPT formulations as per the $2^{3}$ full factorial experimental design

\begin{tabular}{|c|c|c|c|}
\hline Formulation run & $\begin{array}{l}\text { Formulation variable- } X_{1} \text { (amount of } \\
\text { glyceryl behenate, } \% \mathrm{w} / \mathrm{w} \text { of coating) }\end{array}$ & $\begin{array}{l}\text { Formulation variable- } X_{2} \\
\text { (coating level, } \mathrm{mg} \text { ) }\end{array}$ & $\begin{array}{l}\text { Formulation variable- } X_{3} \text { (amount of } \\
\text { sodium chloride, } \% \mathrm{w} / \mathrm{w} \text { of coating) }\end{array}$ \\
\hline PCPT I & $20(-1)$ & $450(-1)$ & $0(-1)$ \\
\hline PCPT 2 & $40(+I)$ & $450(-1)$ & $0(-1)$ \\
\hline PCPT 3 & $20(-I)$ & $650(+I)$ & $0(-1)$ \\
\hline РCPT 4 & $40(+1)$ & $650(+1)$ & $0(-1)$ \\
\hline PCPT 5 & $20(-1)$ & $450(-1)$ & $5(+I)$ \\
\hline РCPT 6 & $40(+I)$ & $450(-1)$ & $5(+I)$ \\
\hline PCPT 7 & $20(-1)$ & $650(+1)$ & $5(+I)$ \\
\hline PCPT 8 & $40(+1)$ & $650(+I)$ & $5(+1)$ \\
\hline
\end{tabular}

Abbreviation: PCPT, press-coated pulsatile tablet.

into the dissolution vessel of the dissolution test apparatus containing $900 \mathrm{~mL}$ of phosphate buffer at $\mathrm{pH}$ 6.8. During the study, assemblies were maintained at $37 \pm 0.5^{\circ} \mathrm{C}$, and aeration was ensured with a continuous supply of bubbled oxygen. Marketed samples of immediate-release aceclofenac and the PCPT developed inhouse with optimum composition was tested $(n=3)$. The drug diffused from the dissolution medium (mucosal side) into the serosal side (absorption compartment) and was analyzed by a validated high-pressure liquid chromatography method ${ }^{20}$ at regular time intervals after filtration through a membrane filter of $0.45 \mu \mathrm{m}$ pore size.

\section{Statistical analysis}

NEMRODW software (LPRAI SARL, Marseille, France) was used for generation of polynomial models, including interaction terms for all response variables using multiple linear regression analysis. Polynomial models together with interaction terms were generated for both the response variables $\left(\mathrm{Y}_{1}\right.$ and $\left.\mathrm{Y}_{2}\right)$ by means of multiple linear regression analysis. The influence of various factors and their interaction with each of the responses are represented graphically. In order to validate the polynomial equations, one optimum checkpoint and three random checkpoints were selected by intensive grid search, performed over the entire experimental domain. Values were predicted for the concentration of glyceryl behenate, sodium chloride, and coating level using a mathematical model developed for the optimized formulation and three additional random checkpoints covering the entire range of the experimental domain. These predicted values were compared with the resulting experimental values and the percentage bias was calculated.

\section{Results and discussion Drug-excipient compatibility studies}

Drug-excipient compatibility studies using differential scanning calorimetry revealed that pure aceclofenac had a sharp melting endothermic peak of $154.49^{\circ} \mathrm{C} .{ }^{23}$ There was no significant change in the endothermic values of aceclofenac after mixing with other excipients compared with those of pure aceclofenac (Figure 1). These observations indicate the absence of any interaction between aceclofenac and the excipients, and therefore suggested compatibility between them. Hence, the excipients selected in this study are suitable for development of this formulation of aceclofenac.

\section{Formulation of core and PCPT of aceclofenac}

Tablets were evaluated for thickness, diameter, hardness, disintegration, friability, and uniformity of weight. The core tablets and different batches of PCPT formulations exhibited uniform thickness and diameter with optimum hardness and friability of less than $1.0 \%$ (Table 3 ). The disintegration time for the core tablets was found to be less than one minute. Rapid disintegration is desirable to get a rapid release after rupture of the coating. The aceclofenac content was found to be $100.45 \%$ of the loaded amount. The release profiles

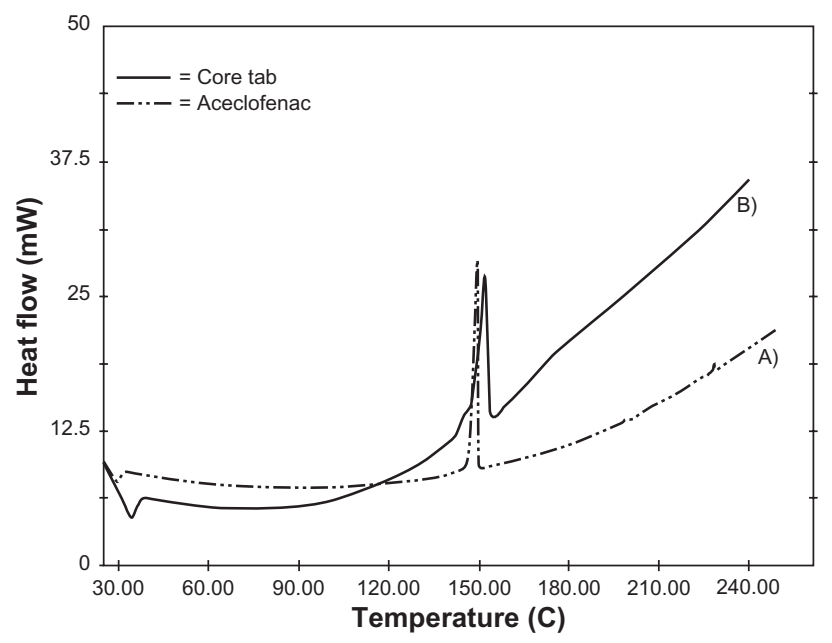

Figure I Overlay differential scanning calorimetry thermograms of A) Pure aceclofenac B) Core tablets of aceclofenac. 
Table 3 Physical characteristics of the core tablets of aceclofenac and all the 8 formulation runs of the aceclofenac PCPT as per the experimental design

\begin{tabular}{|c|c|c|c|c|c|}
\hline & $\begin{array}{l}\text { Thickness }^{\mathrm{a}} \\
(\mathrm{mm})\end{array}$ & $\begin{array}{l}\text { Diameter }^{a} \\
(\mathrm{~mm})\end{array}$ & $\begin{array}{l}\text { Hardness } \\
\left(\mathrm{kg} / \mathrm{cm}^{2}\right)\end{array}$ & $\begin{array}{l}\text { Friability } \\
\text { (\%) }\end{array}$ & $\begin{array}{l}\text { Uniformity of } \\
\text { weight }^{c}\end{array}$ \\
\hline Core tablets & $3.86 \pm 0.28$ & $7.13 \pm 0.62$ & $3.3 \pm 0.4$ & $<1.0$ & -1.5 to +2.1 \\
\hline $\begin{array}{l}\text { PCPT formulation } \\
\text { runs }(I-8)\end{array}$ & $\begin{array}{l}5.44 \pm 0.18 \text { to } \\
6.12 \pm 0.47\end{array}$ & $\begin{array}{l}11.11 \pm 0.26 \text { to } \\
\mid 1.23 \pm 0.31\end{array}$ & $\begin{array}{l}5.2 \pm 0.6 \text { to } \\
5.46 \pm 0.17\end{array}$ & $<1.0$ & -2.8 to +3.6 \\
\hline
\end{tabular}

Notes: ${ }^{M}$ Mean of $6 \pm S D$; ${ }^{b}$ Test performed on number of tablets weighing not less than $6 \mathrm{gms}$; ${ }^{\mathrm{C}}$ Test performed on 20 tablets and value expressed as mean as \% deviation from the average weight.

Abbreviation: PCPT, press-coated pulsatile tablet.

of eight PCPT experimental design batches are shown in Figure 2. Table 4 gives responses observed for $Y_{1}$ (lag time, minutes) and for $\mathrm{Y}_{2}$ (cumulative percentage drug release in 450 minutes) obtained for all the eight experimental runs.

\section{Factorial design}

Experiments were carried out to determine the mathematical relationship between the factors acting on the system and the response of the system. The statistical evaluation of experimental outcomes was processed with NEMRODW software to find the optimum levels of glyceryl behenate and sodium chloride, along with the level of coating that would provide a pulsed burst release from a time-lagged PCPT of aceclofenac. A first order polynomial regression equation that fitted the data is as follows:

$$
\begin{aligned}
\mathrm{Y}= & \mathrm{b}_{0}+\mathrm{b}_{1} \mathrm{X}_{1}+\mathrm{b}_{2} \mathrm{X}_{2}+\mathrm{b}_{3} \mathrm{X}_{3}+\mathrm{b}_{12} \mathrm{X}_{1} \mathrm{X}_{2} \\
& +\mathrm{b}_{13} \mathrm{X}_{1} \mathrm{X}_{3}+\mathrm{b}_{23} \mathrm{X}_{2} \mathrm{X}_{3}+\mathrm{b}_{123} \mathrm{X}_{1} \mathrm{X}_{2} \mathrm{X}_{3}
\end{aligned}
$$

where $b_{0}$ is the arithmetic mean of all the quantitative outcomes of the eight experimental runs; $\mathrm{b}_{1}-\mathrm{b}_{3}$ are the estimated coefficients from the observed experimental values of $Y$ for $\mathrm{X}_{1}, \mathrm{X}_{2}$, and $\mathrm{X}_{3}$. The interactions terms $\mathrm{X}_{\mathrm{i}} \mathrm{X}_{\mathrm{j}} \mathrm{X}_{\mathrm{k}}$ (i, j, and $\mathrm{k}=1,2$, and 3 ) shows how the change in response occurs when two or more factors are simultaneously changed. The equation represents the quantitative effect of factors $\left(\mathrm{X}_{1}\right.$, $\mathrm{X}_{2}$, and $\mathrm{X}_{3}$ ) upon the each of the responses, ie, $\mathrm{Y}_{1}$ and $\mathrm{Y}_{2}$. A positive sign in front of the terms indicates a synergistic effect while a negative sign indicates an antagonistic effect of the factors. The significance of the model was estimated by applying analysis of variance (ANOVA) at the $5 \%$ significance level. A model was considered significant if the $P$ value was less than 0.05 . In addition, graphical analysis by Lenth's method shows that changes of levels that are active on response correspond to bars that exceed the dotted vertical lines, which signify experimental error and give the important factors to be selected (Figures 3A and 3B). ${ }^{24-26}$ Bayesian analysis of coefficients was also carried out (Figures $3 \mathrm{C}$ and 3D). This was an a posteriori calculation of the probability that each of the effects is active and is represented graphically as box plots. ${ }^{26}$

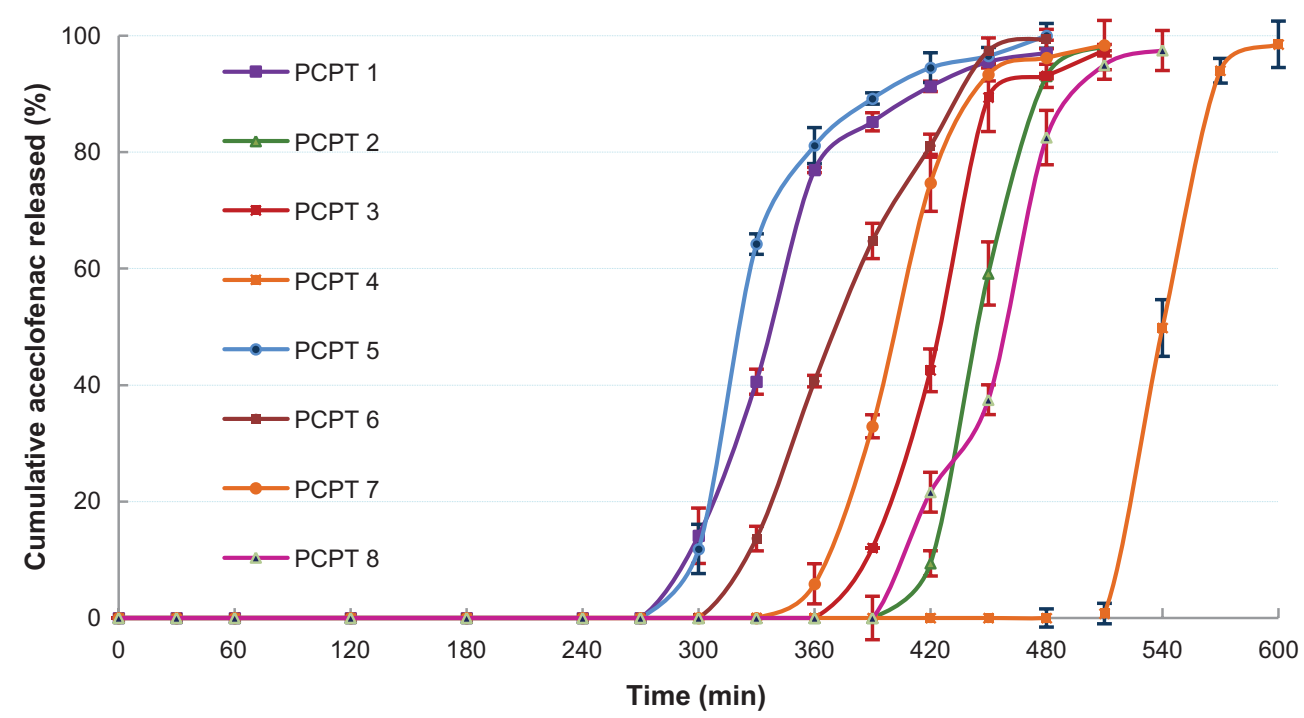

Figure 2 Dissolution profiles of all eight formulation runs as per the factorial design.

Note: $n=6$, Error bars indicate standard deviation.

Abbreviation: PCPT, press-coated pulsatile tablet. 
Table 4 Result data of mean values of various responses, ie, $Y_{1}$ (Lag time, min.) and $Y_{2}$ (\% ACE released in 450 min.) for all the 8 batches of experimental design

\begin{tabular}{|c|c|c|}
\hline \multirow[t]{2}{*}{ Formulation run } & \multicolumn{2}{|l|}{ Responses } \\
\hline & $Y_{1}(\text { Lag time, min. })^{a}$ & $\begin{array}{l}Y_{2}(A C E \text { released } \\
\text { in } 450 \text { min., \%) }\end{array}$ \\
\hline PCPT I & $265 \pm 7.07$ & $95.51 \pm 5.35$ \\
\hline PCPT 2 & $365 \pm 7.07$ & $55.82 \pm 4.04$ \\
\hline PCPT 3 & $387.5 \pm 3.53$ & $89.42 \pm 1.04$ \\
\hline PCPT 4 & $502.5 \pm 10.60$ & $0.00 \pm 0.00$ \\
\hline PCPT 5 & $250 \pm 14.14$ & $97.06 \pm 3.58$ \\
\hline PCPT 6 & $303.5 \pm 4.94$ & $97.84 \pm 2.33$ \\
\hline РСРT 7 & $326 \pm 5.65$ & $93.12 \pm 3.88$ \\
\hline PCPT 8 & $392.5 \pm 8.67$ & $37.47 \pm 3.54$ \\
\hline
\end{tabular}

Note: ${ }^{\text {Mean }}$ of $6 \pm$ SD.

\section{Influence of formulation composition factors on lag time}

Lag time is a highly desirable parameter in pulsatile drug delivery systems. In the present study, the lag time for aceclofenac release was strongly influenced by the coating level and composition.

$$
Y_{1}=345.94+42.19 X_{1}+54.69 X_{2}-34.69 X_{3}
$$
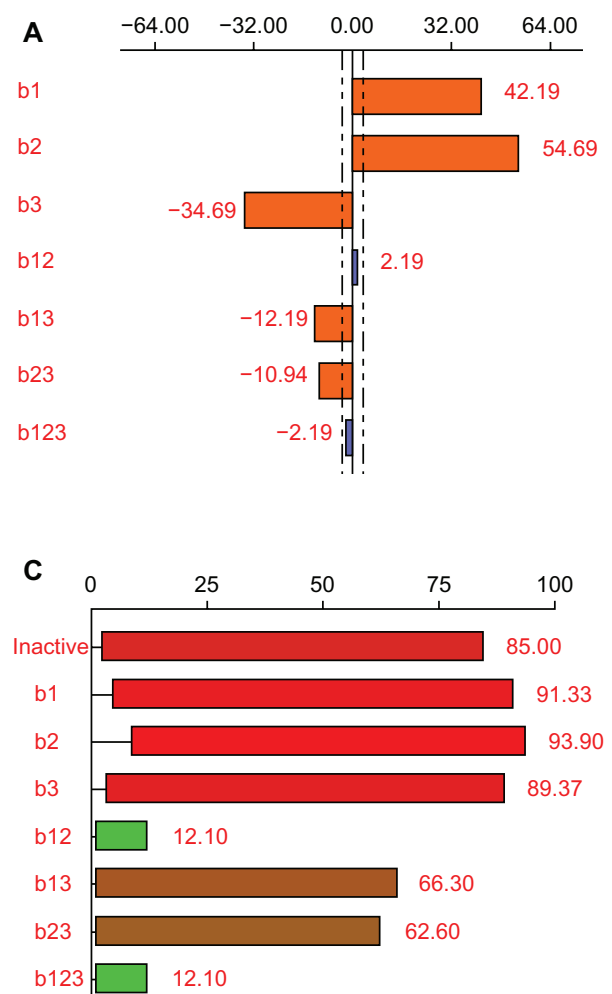

$$
\begin{aligned}
& +2.19 \mathrm{X}_{1} \mathrm{X}_{2}-12.19 \mathrm{X}_{1} \mathrm{X}_{3}-10.94 \mathrm{X}_{2} \mathrm{X}_{3} \\
& -2.19 \mathrm{X}_{1} \mathrm{X}_{2} \mathrm{X}_{3} \\
& \left(\mathrm{~F}=397.61, P \leq 0.0001, \mathrm{r}^{2}=0.997\right)
\end{aligned}
$$

It can be seen from (2), Figure 3A, and the $P$ values of coefficients from Table 5 that the amount of glyceryl behenate and the coating level have a significant effect on lag time. This can be attributed to the hydrophobic nature of glyceryl behenate and the high amount of coating. The negative sign of coefficients of $\mathrm{X}_{3}$ and the interaction terms $X_{1} X_{3}$ and $X_{2} X_{3}$ indicate a negative influence on lag time. Sodium chloride being a highly water-soluble substance undergoes rapid dissolution creating channels in the coat. These channels weaken the strength of the coat and results in rapid burst of coat, thereby reducing the lag time. However, the coefficient values for interaction terms $\mathrm{X}_{1} \mathrm{X}_{2}$ and $\mathrm{X}_{1} \mathrm{X}_{2} \mathrm{X}_{3}$ shows that their interaction was not statistically significant ( $P>0.05$, Table 5$)$. Bayesian analysis of the coefficients (Figure 3C) shows that the effects, $b_{1}, b_{2}$, and $b_{3}$, are active, with probabilities of $91.33 \%, 93.90 \%$, and $89.37 \%$, respectively, and the probability of less active effects, $b_{12}$ and $b_{123}$, was each found to be $12.1 \%$.
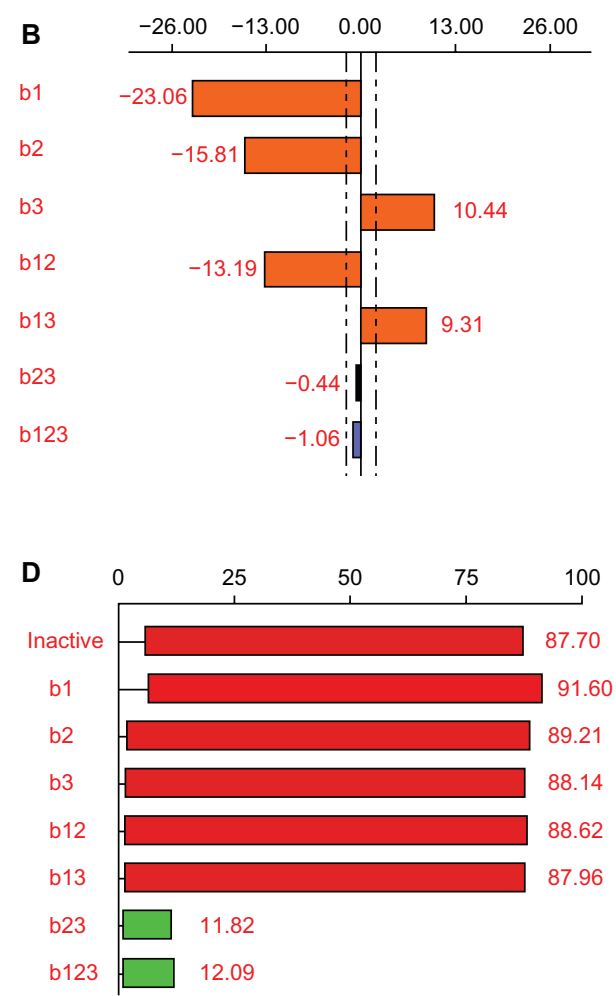

Figure 3 Graphical analysis of effects using Lenth's method on both the responses A) $Y_{1}$, Lag time, and B) $Y_{2}$, ACE released in 450 min. and Bayesian analysis of the coefficients showing probability of each effect's activity for both the considered responses C) $Y_{1}$, Lag time, and D) $Y_{2}$, ACE released in 450 min. 
Table 5 A summary of $P$-values and $F$ values for coefficients of factors for response: $Y_{1}$ (Lag time, min.) and $Y_{2}$ (\% ACE released in $450 \mathrm{~min}$.)

\begin{tabular}{|c|c|c|c|c|}
\hline \multirow[t]{2}{*}{ Coefficient } & \multicolumn{2}{|l|}{$\mathbf{Y}_{1}$} & \multicolumn{2}{|l|}{$Y_{2}$} \\
\hline & $P$ value & $\begin{array}{l}\text { Factor } \\
\text { effect }\end{array}$ & $P$ value & $\begin{array}{l}\text { Factor } \\
\text { effect }\end{array}$ \\
\hline $\mathrm{b}_{1}$ & $<0.000$ I & +42.19 & $<\mathbf{0 . 0 0 0 I}$ & -23.06 \\
\hline$b_{2}$ & $<\mathbf{0 . 0 0 0 1}$ & +54.69 & $<\mathbf{0 . 0 0 0 I}$ & $-|5.8|$ \\
\hline$b_{3}$ & $<\mathbf{0 . 0 0 0 1}$ & -34.69 & $<\mathbf{0 . 0 0 0 I}$ & +10.44 \\
\hline$b_{12}$ & 0.1825 & +2.19 & $<\mathbf{0 . 0 0 0 I}$ & -13.19 \\
\hline$b_{13}$ & $<\mathbf{0 . 0 0 0 1}$ & -12.19 & $<\mathbf{0 . 0 0 0 I}$ & +9.31 \\
\hline$b_{23}$ & $<0.000$ I & -10.94 & 0.6090 & -0.44 \\
\hline$b_{123}$ & 0.1825 & -2.19 & 0.2323 & -1.06 \\
\hline
\end{tabular}

Note: Significant effects of factors $(P<0.05)$ on individual responses are shown in bold type.

\section{Influence of formulation composition factors on drug release}

A pulsatile release profile is characterized by a lag time followed by rapid and complete drug release. After the desired lag time, the onset of release can be achieved by use of a superdisintegrant in the core tablet ${ }^{12}$ and by incorporating channeling agents in the hydrophobic rupturable coat. ${ }^{27}$

$$
\begin{aligned}
\mathrm{Y}_{2}= & 70.31-23.06 \mathrm{X}_{1}-15.81 \mathrm{X}_{2}+10.44 \mathrm{X}_{3} \\
& -12.19 \mathrm{X}_{1} \mathrm{X}_{2}+9.31 \mathrm{X}_{1} \mathrm{X}_{3}-0.44 \mathrm{X}_{2} \mathrm{X}_{3} \\
& -1.06 \mathrm{X}_{1} \mathrm{X}_{2} \mathrm{X}_{3} \\
& \left(\mathrm{~F}=243.7, P \leq 0.0001, \mathrm{r}^{2}=0.995\right)
\end{aligned}
$$

In the present study, the extent of aceclofenac release was mainly influenced by the composition of the rupturable coat. An increase in the concentration of glyceryl behenate and the coating level decreased the release of aceclofenac, as observed from the graphical analysis and negative coefficients of terms $X_{1}$ and $X_{2}$ [(Figure 3B and (3)]. However, $X_{3}$ (amount of sodium chloride) with a positive coefficient relates to an increase in drug release. An increase in the amount of $\mathrm{X}_{3}$ improves aceclofenac release by allowing the dissolution media to penetrate through the coating. In the presence of this penetrated media, the superdisintegrant creates internal pressure causing the core to burst and promotes rapid drug release after the coat ruptures. The results of the Bayesian analysis of coefficients (Figure 3D) are in agreement with Lenth's method. The main effects, $b_{1}, b_{2}$, and $b_{3}$, are active, with probabilities of $91.6 \%, 89.21 \%$, and $88.14 \%$, respectively, and coefficients $b_{23}$ and $b_{123}$ are inactive factors, with probabilities of $11.82 \%$ and $12.09 \%$, respectively.

\section{Optimization using multiple linear regression analysis and validation of mathematical model}

With the help of the aforementioned mathematical models, the formulation was optimized for both responses with the constraints for lag time, $\mathrm{Y}_{1}$ (360 minutes) and aceclofenac release in 450 minutes, $Y_{2}(\geq 90 \%)$. The optimal calculated parameters were

- $\mathrm{X}_{1}=20 \% \mathrm{w} / \mathrm{w}$ of coating (coded value, -1 )

- $\mathrm{X}_{2}=650 \mathrm{mg}$ (coded value, 1 )

- $\mathrm{X}_{3}=2.2 \% \mathrm{w} / \mathrm{w}$ of coating (coded value, 0.12 )

The experiments were carried out according to the composition obtained after applying constraints, and the optimum formulation was evaluated for its dissolution profile. Results obtained for $Y_{1}$ and $Y_{2}$ are shown in Table 6. In order to evaluate the reliability of the mathematical model developed, three additional checkpoints were taken, and estimated using a generated model covering the entire experimental domain. Table 6 gives the levels of variables of optimum formulation and three random checkpoints with their experimental values, predicted values, and the percent bias. The dissolution profiles of aceclofenac showing a lag time followed by burst release from the optimized formulation and the marketed sample were compared and are shown in Figure 4.

For the optimum PCPT, Y 1Experimental $_{\text {was } 358.23}$ ( $\mathrm{Y}_{1}$ predicted, 360.00; percent bias, $-0.49 \%$ ) and $\mathrm{Y}_{\text {2Experimental }}$

\begin{tabular}{|c|c|c|c|c|c|c|}
\hline \multirow[t]{2}{*}{ Responses } & \multicolumn{3}{|l|}{$\mathbf{Y}_{1}$} & \multicolumn{3}{|l|}{$\underline{Y_{2}}$} \\
\hline & Experimental value & Predicted value & Bias (\%) ${ }^{a}$ & Experimental value & Predicted value & Bias (\%) \\
\hline $\mathrm{A}(20,650,2.2)^{\mathrm{b}}$ & 358.23 & 360.00 & -0.4 & 94.27 & 90.53 & 3.96 \\
\hline$B(24.2,650,3.5)^{b}$ & 363.12 & 359.91 & 0.8 & 75.68 & 77.50 & -2.40 \\
\hline$C(40,507,3.025)^{b}$ & 345.48 & 355.22 & -2.0 & 61.72 & 63.89 & -3.57 \\
\hline $\mathrm{D}(37.2,5 \mid 8,2.4)^{\mathrm{b}}$ & 363.71 & 359.99 & 1.0 & 58.33 & 61.05 & -4.66 \\
\hline
\end{tabular}
was found to be 94.27 ( $\mathrm{Y}_{2}$ predicted, $90.53 \%$; percent bias,

Table 6 The experimental and predicted values for responses $Y_{1}$ (Lag time in min.) and $Y_{2}$ (ACE released in 450 min) along with percentage prediction error observed for optimum formulation $(A)$ and random formulation $(B, C$ and $D)$

Notes: ${ }^{a}$ Bias $(\%)=\left(\right.$ experimental value-predicted value)/experimental value $\times 100 ;{ }^{b}$ The values represented in the brackets are the amount of $\mathrm{GB}$ in $\% \mathrm{w} / \mathrm{w}, \mathrm{Coating}$ level in $\mathrm{mg}$, amount of sodium chloride in $\% \mathrm{w} / \mathrm{w}$ respectively. 


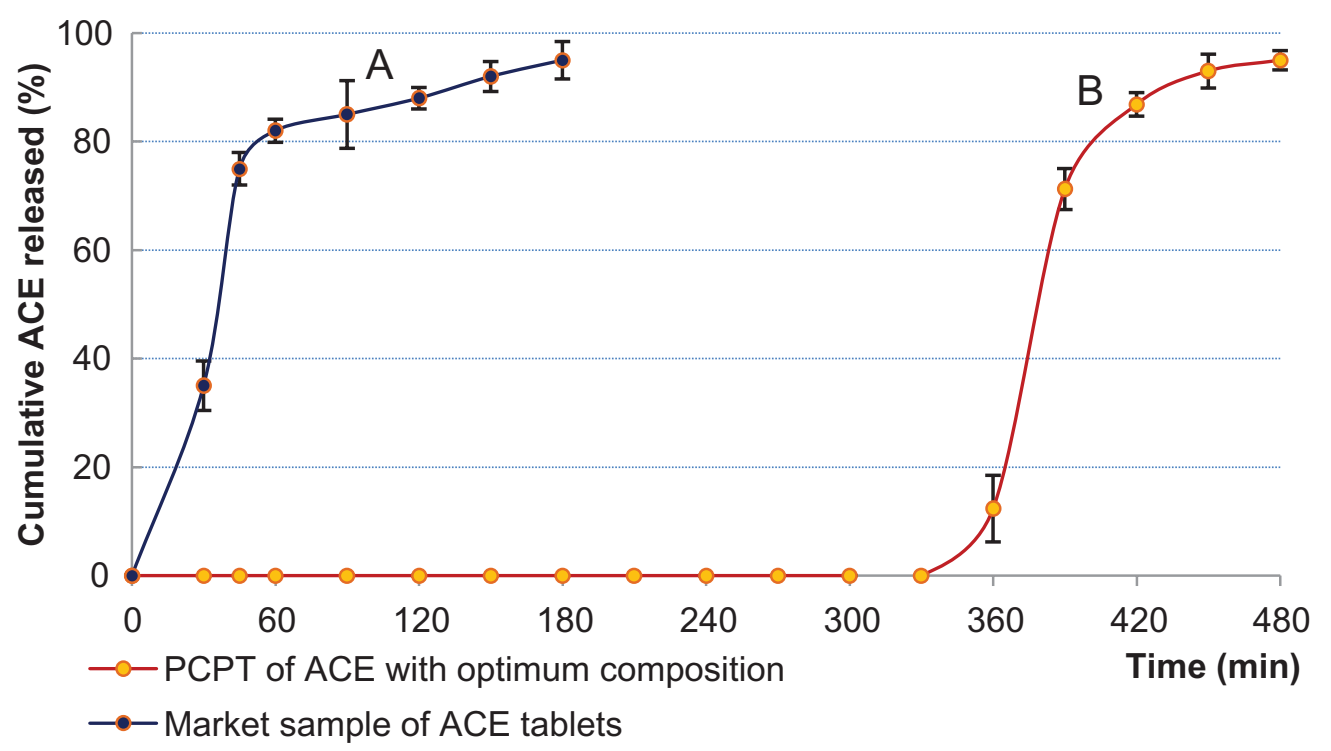

Figure 4 Complete dissolution profile of ACE tablet A) Obtained from the market and B) PCPT of ACE with optimized composition. Note: $\mathrm{n}=6$, Error bars indicate standard deviation.

$3.96 \%)$ as shown in Table 6 . Thus, the lower values of percent bias ( -0.4 to 1.0 for $\mathrm{Y}_{1}$ and -4.66 to 3.66 for $\left.\mathrm{Y}_{2}\right)$ in the current study indicate the robustness of the mathematical model. Furthermore, the dissolution profile of the optimized PCPT formulation was compared with the marketed sample of immediate-release aceclofenac $100 \mathrm{mg}$. The marketed sample showed $>70 \%$ of aceclofenac release in 45 minutes and approximately $95 \%$ release in 180 minutes when tested in $900 \mathrm{~mL}$ of pH 6.8 phosphate buffer (Figure 4). The PCPT formulation showed a lag time of 360 minutes followed by rapid release of approximately $95 \%$ at 450 minutes (Figure 4). Rupture behavior of PCPT for aceclofenac with optimum composition was photographed by a digital camera (Olympus FE25.X20, Olympus, China) and is shown in Figure 5.

\section{Dissolution-ex vivo permeation study using rat everted intestine}

In the dissolution-ex vivo permeation study, the amount of aceclofenac absorbed ex vivo (\%) and the amount of

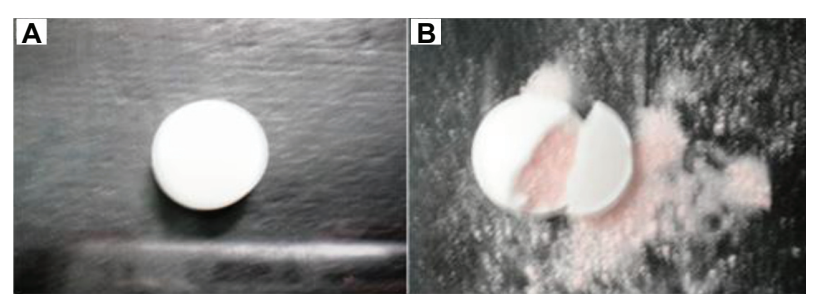

Figure 5 Rupture behavior of press coated pulsatile tablet of aceclofenac at A) $120 \mathrm{~min}$. and B) $390 \mathrm{~min}$. aceclofenac dissolved in vitro (\%) were correlated, and are shown in Figures 6A and 6B for the optimized PCPT of aceclofenac and the marketed immediate-release tablet of aceclofenac, respectively. A third order polynomial relationship was found to be the best fit for the dissolution-ex vivo permeation study of aceclofenac for both the formulations. A good point-to-point relationship was observed between
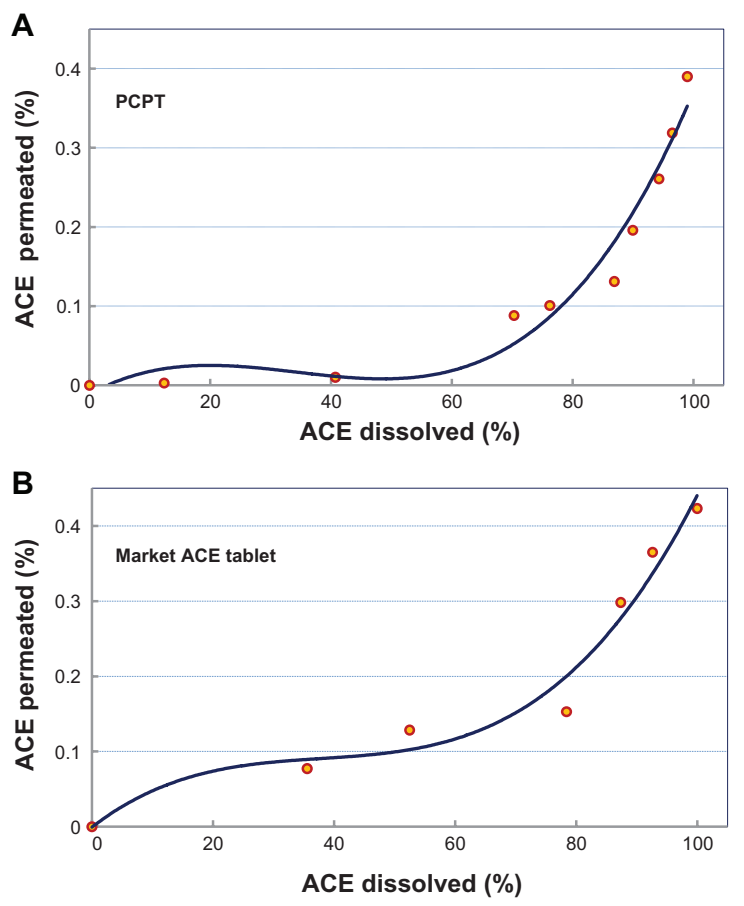

Figure 6 Correlation between in vitro dissolution and ex vivo permeation of ACE studied using everted rat intestine segment A) Optimized PCPT formulation of ACE B) Marketed sample ACE tablet (Immediate release). 
the fraction of aceclofenac dissolved and the fraction of aceclofenac permeating into the intestinal segment, with a regression coefficient of 0.961 and 0.969 for the PCPT and immediate-release aceclofenac tablets, respectively. This indicates that the permeation behavior was not significantly altered for the PCPT of aceclofenac.

\section{Conclusion}

Optimization of PCPT for aceclofenac was carried out using a three-factor, two-level, full factorial design. This allowed rapid evaluation and identification of the parameters important in determining the desired responses, ie, the lag time for aceclofenac release and the release of aceclofenac over 450 minutes. The effect of varying the amounts of glyceryl behenate and sodium chloride, as well as the coating level, on lag time and drug release was investigated. A quantitative relationship between the amount of glyceryl behenate, amount of sodium chloride (channeling agent), level of coating over the core, and the release profile of aceclofenac from the PCPT tablet was developed.

In particular, graphical analysis of effects by Lenth's method and Bayesian analysis of coefficients enabled identification of each examined variable active on the selected responses. The mathematical model for each of the responses developed using multiple regression analysis quantitatively describes the influence of the selected variables on the responses under investigation. From the significance of the main effects and their interactions, it was possible to predict the influence of the factors within the defined experimental domain.

The observed responses for the optimum formulation were in close agreement with the predicted values, indicating excellent predictability of the optimization procedure. The optimized formulation displayed a lag time of 358.23 minutes followed by rapid release of aceclofenac at $94.27 \%$, and mimicking the fluctuating symptoms of rheumatoid arthritis.

The novel PCPT developed for aceclofenac could be a promising chronomodulated therapeutic system for the relief of morning stiffness in patients with rheumatoid arthritis. The technology used for the preparation of PCPT is a relatively simple manufacturing process which can be easily adopted in industrial units on a commercial scale.

\section{Acknowledgment}

The generosity of Astron Research Ltd, India, and Gattefosse, France, is gratefully acknowledged for providing samples of aceclofenac and glyceryl behenate, respectively.

\section{Disclosure}

The authors report no conflicts of interest in this work.

\section{References}

1. Anal AK. Time-controlled pulsatile delivery systems for bioactive compounds. Recent Pat Drug Deliv Formul. 2007;1:73-79.

2. Lemmer B. Chronobiology, drug-delivery, and chronotherapeutics. Adv Drug Deliv Rev. 2007;59:825-827.

3. Smolensky MH, Peppas NA. Chronobiology, drug delivery and chronotherapeutics. Adv Drug Deliv Rev. 2007;59:828-851.

4. Bussemer T, Otto I, Bodmeier R. Pulsatile drug-delivery systems. Crit Rev Ther Drug Carrier Syst. 2001;18:433-458.

5. Roy P, Shahiwala A. Multiparticulate formulation approach to pulsatile drug delivery: Current perspectives. J Control Release. 2009;134: $74-80$.

6. Krogel I, Bodmeier R. Pulsatile release from an insoluble capsule body controlled by an erodible plug. Pharm Res. 1998;15:474-480.

7. Ross A. Chronopharmaceutical drug delivery from a pulsatile capsule device based on programmable erosion. J Pharm Pharmacol. 2000;52: 903-909.

8. Ueda S, Hata T, Asakura S. Development of a novel drug release system, time-controlled explosion system (TES). I. Concept and design. J Drug Target. 1994;2:35-44.

9. Efentakis M, Koligliati S, Vlachou M. Design and evaluation of a dry coated drug delivery system with an impermeable cup, swellable top layer and pulsatile release. Int J Pharm. 2006;311:147-156.

10. Pozzi F, Furlani P, Gazzaniga A, Davis SS, Wilding IR. The Time Clock $^{\mathbb{B}}$ system: A new oral dosage form for fast and complete release of drug after a predetermined lag time. J Control Release. 1994;31: 99-108.

11. Sungthongjeen S, Puttipipatkhachorn S, Paeratakul O, Dashevsky A, Bodmeier R. Development of pulsatile release tablets with swelling and rupturable layers. J Control Release. 2004;95:147-159.

12. Sinha VR, Bhinge JR, Kumria R, Kumar M. Development of pulsatile systems for targeted drug delivery of celecoxib for prophylaxis of colorectal cancer. Drug Deliv. 2006;13:221-225.

13. Malah YE, Nazzal S. Novel use of Eudragit ${ }^{\circledR}$ NE 30D/Eudragit ${ }^{\circledR}$ L 30D-55 blends as functional coating materials in time-delayed drug release applications. Int J Pharm. 2008;357:219-227.

14. Roy P, Shahiwala A. Statistical optimization of ranitidine $\mathrm{HCl}$ floating pulsatile delivery system for chronotherapy of nocturnal acid breakthrough. Eur J Pharm Sci. 2009;37:363-369.

15. Bussemer T, Peppas NA, Bodmeier R. Time-dependant mechanical properties of polymeric coatings used in rupturable pulsatile release dosage forms. Drug Dev Ind Pharm. 2003;29:623-630.

16. Dashevsky A, Bussemer T, Mohamad A, Bodmeier R. Process and formulation variables affecting the performance of a rupturable capsule based drug delivery system with pulsatile drug release. Drug Dev Ind Pharm. 2004;30:171-179.

17. Fukui E, Miyamura N, Uemura K, Kobayashi M. Preparation of enteric coated timed-release press-coated tablets and evaluation of their function by in-vitro/in-vivo test for colon targeting. Int J Pharm. 2000; 204:7-15.

18. Arvidson NG, Gudbjörnsson B, Elfman L, Rydén AC, Tötterman TH, Hällgren R. Circadian rhythm of serum interleukin-6 in rheumatoid arthritis. Ann Rheum Dis. 1994;53:521-524.

19. Indian Pharmacopoeia. Ministry of Health and Family Welfare, Government of India, Controller of Publication, India. 2007:182-183.

20. Indian Pharmacopoeia. Ministry of Health and Family Welfare, Government of India, Controller of Publication, Delhi, India. 2007: 682-683.

21. Kale VV, Kasliwal RH, Avari JG. Attempt to design continuous dissolution-absorption system using everted intestine segment for in vitro absorption studies of slow drug release formulations. Dissolution Technologies. 2007;14:31-36. 
22. Mariappan TT, Singh S. Evidence of efflux-mediated and saturable absorption of rifampicin in rat intestine using the ligated loop and everted gut sac techniques. Mol Pharm. 2004;1:363-367.

23. Mutalik S, Anju P, Manoja K, Ushaa AN. Enhancement of dissolution rate and bioavailability of aceclofenac: A chitosan-based solvent change approach. Int J Pharm. 2008;350:279-290.

24. Pund S, Joshi A, Vasu K, Nivsarkar M, Shishoo C. Multivariate optimization of formulation and process variables influencing physicomechanical characteristics of site-specific release isoniazid pellets. Int J Pharm. 2010;388:64-72.
25. Furlanetto S, Cirri M, Maestrelli F, Corti G, Mura P. Study of formulation variables influencing the drug release rate from matrix tablets by experimental design. Eur J Pharm Biopharm. 2006;62:77-84.

26. Lewis GA, Mathieu D, Phan-Tan-Luu R. Pharmaceutical Experimental Design. New York, NY: Marcel Dekker Inc; 1999.

27. Gonzalez-Rodriguez ML, Perez-Martinez JI, Merino S, Fini A, Rabasco AM. Channeling agent and drug release from a central core matrix tablet. Drug Dev Ind Pharm. 2001;27:439-446.

\section{Publish your work in this journal}

ChronoPhysiology and Therapy is an international, peer-reviewed, open access journal focusing on research into the cyclic variations and rhythmicity in physiological processes in the body and the research and development and optimal timing of administration of therapeutic targets to achieve improved outcomes and quality of life for the patient. The

\section{Dovepress}

manuscript management system is completely online and includes a very quick and fair peer-review system. Visit http://www.dovepress.com/ testimonials.php to read real quotes from published authors. 